\title{
Layoffs as Part of an Optimal Incentive Mix: Theory and Evidence
}

\author{
Anders Frederiksen* and Előd Takáts ${ }^{\dagger}$
}

September 19, 2005

\begin{abstract}
Firms offer highly complex contracts to their employees. These contracts contain a mix of various incentives, such as fixed wages, bonuses, promise of promotion, and threat of firing. This paper aims at explaining the reason why this incentive-mix arises. In particular, the model focuses on why firms are combining promotions and bonuses with firing. The theoretical model proposed is a job-assignment model with heterogeneous employees. In this model the firm is concerned about job assignment, because the overall productivity of the firm depends upon the quality of the employees and their allocation to jobs. The model shows that firing has a dual role. Firing creates incentives for the employees, and it is used as a sorting device that allows the firm to improve workforce quality. Thus, quality-concerned firms might want to combine cost-efficient incentives such as promotions and bonuses with firing. To comply with the Gibbons and Waldman critique, a large set of the model's broader predictions is stated explicitly and tested on the personnel records from a large pharmaceutical company. The model's predictions are shown to be consistent with the data.
\end{abstract}

JEL codes: J30, J41, M50

Keywords: Personnel Economics, Incentive Mix, Layoffs

We are greateful for the comments and suggestions given by Ann Bartel, Patrick Bolton, Henry Farber, Jeremy Fox, Mike Gibbs, Bo Honoré, Ed Lazear, Bentley MacLeod, Jesse Rothstein, Kathryn Shaw, and Niels Westergaard-Nielsen. We are also thankful for the comments given by workshop and conference participants at Princeton University, the Center for Corporate Performance (CCP), the European Economic Association Amsterdam Conference, the First Annual IZA Workshop on Behavioral and Organizational Economics, the Aarhus School of Business, and the 12th Panel Data Conference at the Center for Applied Microeconometrics (CAM). Anne Raaby Olsen has provided able research assistance.

This research project has been supported financially by the Danish Social Science Research Council through a grant to the Center for Corporate Performance.

Elód Takáts is grateful for hospitality while conducting research at the CCP at the Aarhus School of Business, and for financial support from the Gregory C. Chow Econometric Research Program.

*Stanford University, Hoover Institution, National Fellow, 2005-2006 and the Aarhus School of Business; Center for Corporate Performance (CCP) and the Institute for the Study of Labor (IZA); email: afr@asb.dk

${ }^{\dagger}$ Princeton University, Department of Economics; email: elod@princeton.edu 


\section{Motivation}

Firms use a variety of economic incentives to motivate their employees. Fixed wages, bonuses, promise of promotion, and threat of firing are the most frequently used ones. In general, economists understand why firms choose to use various incentives, but not why firms would prefer a specific mix. Understanding the reasons why such a mix arises has strong policy implications, besides contributing to our understanding of personnel economics. The reason is that in many markets firing, an important piece of the incentive mix, is constrained. Thus, understanding the economic role of the incentive mix, and in particular the role of firing, provides yet another angle to evaluate the effects of labor-market regulations. This paper presents a theoretical model of how incentives are used in firms, and provides empirical evidence showing that firms that are concerned about the quality of the workforce, may have strong interests in using firing. Consequently, quality-concerned firms in heavily regulated markets might face comparative disadvantage when competing internationally, because they are forced to undertake second-best personnel policies.

Traditionally, it has been difficult to obtain detailed information on the compensation systems used in firms. Nevertheless, the evidence that firms use a rich set of incentives is accumulating see Medoff and Abraham [1980, 1981]; Baker, Gibbs, and Holmström [1994a,b]; Gibbs [1995]; and Lazear [1992, 2000]. To conduct the present analysis of within firm incentives we have successfully obtained the personnel records from a large pharmaceutical firm, in which the four incentives: fixed wages, bonuses, promise of promotion, and threat of firing are observed. This detailed information, and in particular the observed role of firing, makes these data well-suited to investigate the incentive-mix in a joint theoretical-empirical framework.

Conventional economic theory motivates the use of the different incentive mechanisms in separate frameworks. First, the performance-pay literature, which originates from Mirrlees [1974, 1976] and Holmström [1979, 1982], explains why pay should be linked to output. According to this theory, wages should include variable elements, such as bonuses or piece rate, to reward employee effort. Second, the efficiency-wage literature started off by Shapiro and Stiglitz [1984] emphasizes the incentive-effect of firing, or the threat of firing. Intuitively, if employment involves rents, then the fear of losing the job provides incentives.

Tournament theory, initiated by Lazear and Rosen [1981], integrates the usage of the incentives in a competitive framework. If the number of workers rewarded, fired, or promoted is preset, then workers have an incentive to exert effort. In principle, tournament theory explains why firms would use any element of the mix. Tournament theory cannot explain, however, why the firm would prefer a specific mix of incentives.

MacLeod and Malcolmson [1998] analyze the relative merits of different incentive tools. They contrast efficiency-wage and performance-pay incentives, that is, firing and bonus payments as incentive tools. Under the efficiency wage system, firms pay rents ex-ante, and provide incentives by firing shirking workers. Under the performance-pay regime, firms pay bonuses ex-post, conditional on effort. The model shows that, in general, efficiency-wage incentives are more expensive. Yet, efficiency wage might arise because it gives compensation upfront. Hence, if the firm cannot commit to pay bonuses, then efficiency wages might be the only way to motivate employees. The results, however, do not answer the question why the observed incentive mix can arise. In the MacLeod and Malcolmson [1998] setup, either efficiency wage or performance pay prevails.

Our basic model, which is a traditional principal-agent model with hidden effort, is set in 
a two period setup. The first period is in the focus of our investigation, when the firm offers employment contract in terms of fixed wages, bonuses and firing and promotion probabilities. It is shown that the optimal behavior of the firm is to motivate the employees through bonus payments and promotions, but it should not fire employees. Thus, the incentive mix observed in firms does not arise. The reason is that in contrast to promotions and bonus payments, firing is wasteful. Firing is costly both for the firm (recruiting and training of new employees) and for the worker (job search), and in equilibrium the firm shoulders all these costs. Thus, the firm prefers to offer promotions and bonuses over threatening employees with layoffs.

The basic model is extended to accommodate employee-heterogeneity. The profit-maximizing firm is now concerned about job assignment, because the overall productivity of the firm in the second period depends upon the quality of the employees and their allocation to jobs. These concerns create a trade-off for the firm. Increasing firing induces additional costs on the firm. Firing, however, also increases second period employee quality. This trade-off explains why the firm might prefer to use the delicate mix of incentives, which is observed in the data.

The paper shows that the incentive-mix, and, in particular, firing, has profound implications for the within-firm dynamics. These implications are explored to characterize employees' careers. In particular, it is shown that within organizational rank, selection on tenure is not necessarily negative as argued in earlier research by Medoff and Abraham [1980, 1981], Lazear [1992, 2000], Gibbs [1995], and Gibbons and Waldman [1999a,b]. The empirical analysis confirms this theoretical result by providing the first example for positive within organizational rank selection on tenure. This finding shows, as Guasch and Weiss [1980] suggest, that selection constitutes an interesting alternative to on-the-job human-capital acquisition to explain the effects of tenure on earnings. In fact, selection alone can justify a positively sloped earning profile in tenure.

The model's additional predictions about the employee's careers are tested formally in the empirical section of the paper. Contrasting the broad set of predictions to data is used to comply with the Gibbons and Waldman [1999a,b] critique, namely that many models may be able to explain a single empirical finding (such as the observed incentive mix), but they often fail to explain a broader pattern of empirical evidence. First, it is confirmed that the firm engages in sorting based on performance which is a basic assumption of the job assignment model. Second, it is established that the firm has a positive selection, i.e., individuals with higher rank and higher tenure are more likely to be of high-ability. Also, the model's predictions about the likelihood of receiving bonus payments, being promoted and being laid off, are shown to be consistent with the data.

In the next section, the basic model is outlined. Section 3 extends this model to accommodate employee heterogeneity and address the consequences of sorting and selection for the employees' career evolution. Furthermore, the predictions of the theoretical model are stated here. The data are presented in section 4 , and the close relation between the empirical contract and the theoretical model is emphasized. In section 5, the model's predictions are tested empirically. A detailed discussion of the model's limitations and suggestions for future research takes place in section 6. Finally, section 7 summarizes and concludes. 


\section{Basic model}

The basic model entails the contracting relationship between a risk-neutral firm and a continuum of risk-neutral employees in a two period game. The firm and the employees form a principalagent relationship. The firm maximizes expected profit, while the employees maximize their expected utility.

The game is divided in two periods. The first period is the more interesting for our purposes, where the firm offers an employment contract in terms of fixed wage, bonus, firing and promotion. The timing of events in the first period is as follows:

1. The firm offers a contract to prospective employees. If they accept it, they are hired.

2. Employees decide about the effort level.

3. Output is realized and observed by all.

4. Bonuses are paid; employees are promoted or fired.

In the second period the firm has two actions. First, it has to fill management vacancies which can be done either by promotions or external hiring. Second, employees leaving the nonmanagement level due to layoffs or promotions have to be replaced. Furthermore, retained and newly hired employees produce output without an explicit incentive problem. ${ }^{1}$

The employees produce binary output in the first period, which is normalized to 0 (low) or $C$ (high), where $C>0$. The probability that the output is $C$, is $\theta$ and naturally $\theta \in(0,1)$. The employee, once having accepted the job, can influence the probability of high output by exerting effort. The utility cost of effort exertion is $e$, and effort increases the probability of success by $\delta>0$. The table below summarizes the probabilities:

$$
\begin{array}{lll} 
& \text { without effort } & \text { with effort } \\
\text { low output }(0) & 1-\theta & 1-\theta-\delta \\
\text { high output }(C) & \theta & \theta+\delta
\end{array}
$$

The effort is worth undertaking, i.e. the private costs of effort are strictly less than the production gains, formally: $e<\delta C$. We further assume that $\theta+\delta<1$.

The utility of the employee's alternative job option is denoted by $\bar{U}>0$. Furthermore, the additional utility of a promotion is $U_{P}>0$, and the utility cost from being fired is $U_{F}>0$. The utility of promotion stems from managerial rents, and is discussed in detail in the appendix. The utility loss from firing reflects that if an employee is laid off, then he or she must search for a new job, which is costly, as there are frictions on the labor market.

The firm sets the first period employment contract through the following four parameters: $\left\{w, b, \pi_{P}, \pi_{F}\right\}$. First, a fixed wage $(w)$ is offered to all individuals who accept the job irrespective of performance. The remaining three parameters are conditioned on performance. It is assumed that bonus payments $(b)$ are paid to well-performing agents, that the firm considers promoting employees with high observable output (high performance), and considers firing employees with low observed output (low performance). The conditional promotion probability and

\footnotetext{
${ }^{1}$ Thus, the second period can be interpreted as the long run consequence of first period job assigment decisions. Incentive problems are abstracted away to help focus on the first period problem.
} 
the conditional firing probability are denoted by $\pi_{P}$ and $\pi_{F}$, respectively. The parameters are (realistically) constrained as follows: $w, b \geq 0 ; \pi_{F}, \pi_{P} \in[0,1] .^{2}$

Turnover is costly, as the firm has replacement and training costs. These costs are summarized in the turnover-cost parameter $K>0$. This implies that costs are imposed on the firm when it fills management vacancies but also when it decides to layoff employees. The equilibrium volume of firm-initiated separations is $(1-\theta-\delta) \pi_{F}$ in equilibrium. ${ }^{3}$

The employees desire promotion to management, because promotion entails rent. The number of employees who can be promoted is, however, constrained by the number of vacant positions at the management level. That is, the volume of promotions $(\theta+\delta) \pi_{P}$ is constrained by the volume of exogenous job openings at the managerial level, which is normalized to $1 / H$. Parameter $H$ can be interpreted as a hierarchy size difference between employee and managerial rank. The above argumentation is summarized in the promotion-constraint $(P)$ :

$$
(\theta+\delta) \pi_{P} \leq \frac{1}{H}
$$

It is assumed that $(\theta+\delta)<H$, which implies that not all well-performing employees can be promoted. ${ }^{4}$

In the second period, the firm has two hierarchical ranks: employees and managers. ${ }^{5}$ Employees uniformly produce output $F$. Furthermore, employee compensation in the second period is normalized to zero.

$\begin{array}{ll}\{0, C\} & \text { output realizations } \\ M & \text { managerial output } \\ F & \text { output in the second period } \\ \theta & \text { probability that output is high } \\ \delta & \text { probability increase with effort } \\ e & \text { effort cost } \\ \bar{U} & \text { utility of alternative job option } \\ U_{P} & \text { utility of a promotion } \\ U_{F} & \text { utility cost from being fired } \\ H & \text { size-ratio of managerial and employee rank } \\ w & \text { fixed wage } \\ b & \text { bonus paid conditional on high output } \\ \pi_{P} & \text { probability of promotion conditional on high output } \\ \pi_{F} & \text { probability of firing conditional on low output }\end{array}$

Table 1: Model parameters

Managers consist of formerly promoted non-management employees and individuals hired from the external labor market directly into management. Managerial incentives and participa-

\footnotetext{
${ }^{2}$ Conditioning bonus, promotion and firing on output as above can be done without the loss of generality, which can be seen from the discussion in the appendix.

${ }^{3}$ In equilibrium the firm will elicit high effort.

${ }^{4}$ The assumption is realistic and used only to ease the exposition. It does not change the results.

${ }^{5}$ The two layer hierarchy provides the simplest setting to analyze the employee incentive mix without analyzing complicated multi-layer hierarchies. Furthermore, only $5 \%$ of the observations in our data considers managers, thus theoretical findings on management rank would be hard to verify empirically.
} 
tion are not modeled explicitly and assumed to contribute to the firm's profit with a fixed-value $M$. We assume that $F<M$, i.e. managerial output is more important than employee output in the second period. This follows from the fact that managers affect the output of multiple non-management employees. Managers pay is also normalized to zero. ${ }^{6}$

In order to keep the analysis tractable, it is assumed that the firm has all the bargaining power. Furthermore, two tie-breaking rules are imposed. First, indifferent players act such that the other player is better off. Second, employees are assumed to prefer less risky payments with the same mean. ${ }^{7}$ Finally, the observed incentive mix is defined as the equilibrium in which the firm strictly prefers to set all the parameters $\left\{w, b, \pi_{P}, \pi_{F}\right\}$ to non-zero values.

\subsection{Contracting problem}

The contracting problem is summarized in the following equations:

$$
\max _{w, b, \pi_{F}, \pi_{P}}(\theta+\delta) C+M / H+F-w-(\theta+\delta) b-(1-\theta-\delta) \pi_{F} K-\frac{K}{H}
$$

subject to

$$
\begin{aligned}
& (I C) \quad w-e+(\theta+\delta)\left[b+\pi_{P} U_{P}\right]-(1-\theta-\delta) \pi_{F} U_{F} \geq w+\theta\left[b+\pi_{P} U_{P}\right]-(1-\theta) \pi_{F} U_{F} \\
& (I R) \quad w-e+(\theta+\delta)\left[b+\pi_{P} U_{P}\right]-(1-\theta-\delta) \pi_{F} U_{F} \geq \bar{U} \\
& (\theta+\delta) \pi_{P} \leq \frac{1}{H} \\
& \text { probability } \\
& w, b \geq 0 \\
& \pi_{F}, \pi_{P} \in[0,1]
\end{aligned}
$$

Intuitively, the program above states that the firm maximizes profit. Employees contribute to firm profit by providing the high output $C$, with probability $(\theta+\delta)$ in the first period. In the second period managers and employees both contribute to firm profitability. Each manager contributes to the profit by $M$, and their number is $1 / H$, employees produce $F$ output.

In exchange, employees are compensated. The firm pays fixed wages $(w)$ with certainty, and bonuses $(b)$ with probability $(\theta+\delta)$. In addition, the firm has to incur costs of turnover $(K)$ from two sources. First, the firm fires badly performing employees with probability $\pi_{F}$. Second, the firm has to hire (either directly to management or employee level) volume $1 / H$ employees either to fill management positions or to replace promoted employees. Finally, manager and employee pay is normalized to zero in the second period, so it is not displayed.

The $I C$-constraint implies that the employee accepting the contract is better off by exerting the first-best high effort in the first period. The left-hand side shows the worker's utility given effort. The employee receives the fixed wage $(w)$, and incurs the cost of effort $(e)$. Furthermore, the probability $(\theta+\delta)$ of high output leads to a relatively high probability of receiving bonus payments $(b)$ and promotion $\left(\pi_{P}\right)$, which provides utility $\left(U_{P}\right)$. Also, the employee has a lower probability $(1-\theta-\delta) \pi_{F}$ of being fired, and hereby incurring the disutility $\left(U_{F}\right)$. The right-hand side shows the worker's compensation without effort-exertion. Here the chances for bonuses and

\footnotetext{
${ }^{6}$ Modeling managerial incentives is thus entirely absent from the model. The reason is twofold. First, it suffices for our theoretical point to show the emergence of the observed incentive mix at the employee level. Second, as our data is sparse on managers, the theoretical results would be impossible to test.

${ }^{7}$ This can be interpreted as moderate form of risk aversion.
} 
promotions are lower $(\theta)$, and that of firing $(1-\theta) \pi_{F}$ is higher. Thus, in principle, bonuses, promotions, and firing are used to induce effort.

The $I R$-constraint states that the employee is better off accepting the contract. The left-hand side of the equation is the same as in the $I C$-constraint, i.e., the utility with exerting effort. This utility must exceed the utility of the employee's outside option $(\bar{U})$.

The other constraints follow from the assumptions directly. Wages and bonuses must be non-negative, as the non-negativity constraints say. Finally, conditional firing and promotion probabilities must be on the unit interval.

\subsection{Solving the basic model}

Notice first, that in equilibrium the promotion constraint $(P)$ is always binding. ${ }^{8}$ If $P$ is slack, then the firm can increase promotions, and in exchange decrease bonuses, fixed wages, costly firing or it can increase employee welfare. The firm can increase its profits, if fixed wages, bonuses or the firing parameter are non-zero. Even if all of them take zero values, the firm can increase the welfare of its employees without additional costs. Thus, in equilibrium in the basic model the $P$ constraint is binding. In other words, there is ports of entry as suggested in Doeringer and Piore [1971].

Furthermore, by definition the observed incentive mix arises only if all four parameters are set to non-zero values. Thus, it is enough to focus our attention to binding $I R$ - and $I C$-constraints. To see that consider the following. First, in profit maximizing equilibrium the individual rationality $(I R)$ constraint binds or the wage is set to zero. If it does not bind, then the wage must be zero else the firm would reduce the fixed wage, and thereby increase its profit.

Similarly, the incentive compatibility constraint $(I C)$ binds or the bonus is set to zero in equilibrium. If the $I C$-constraint does not bind, then the bonus must be zero else the firm would decrease bonus payments. If $I R$-constraint binds, the firm can lower bonus payments (and increase fixed wages) to make the employees better off. If the $I R$-constraint does not bind, the firm can lower bonus payments without wage compensation and increase profits.

In sum, the observed incentive mix can only arise, when all the $I R$-, $I C$ - and $P$-constraints bind. Consequently, whenever the observed incentive mix is possible, the original four-parameter incentive problem is reduced to a single-parameter optimization. Expressing the profit as a function of $\pi_{F}$, the first-order condition reveals that the objective function is maximized when the firing rate is minimized and set to zero. Thus, the observed incentive mix cannot arise in the basic model.

The intuition is that firing is more costly than bonuses to motivate workers. Firing creates two social costs: cost of hiring and utility loss of firing. In equilibrium, these two costs are born by the firm. Consequently, firing is necessarily set to zero. Lemma (1) summarizes the result. The proof of the lemma is provided in the appendix as well as the proof of other statements.

Lemma 1 In the basic model incentives are given through bonuses and promotions, but not through firing. Thus, the observed incentive-mix does not arise.

The results of the basic model also can be interpreted as evidence for a hierarchy of incentives. The firm prefers to use promotions, because they exploit costless residual rents. If additional

\footnotetext{
${ }^{8}$ Binding $P$ constraint implies a less than unity promotion parameter by the restriction on $H$.
} 
incentives are needed (to satisfy the $I C$-constraint), then the firm turns to using bonuses. Finally, to ensure worker participation (and to satisfy the $I R$-constraint), the firm uses fixed wages, but only if bonuses and promotions are insufficient. Firing, however, is never used, because of its cost-disadvantage.

Finally, a few words about rents in the model. There is no ex-ante rent by assumption (as the individual rationality constraint $(I R)$ is binding). However, the fact that firing causes disutilities $\left(U_{F}\right)$ shows that interim there is rent. The interpretation is, that even though the worker is initially indifferent between the firm's offer and other offers, going back to the labor market and starting to search is costly. Thus, interim, there is rent from retaining the job, and the firm can exploit this feature to motivate the worker. Lemma (1) states, however, that motivating through layoffs is more costly than motivating through bonus payments.

\section{Job-assignment model}

In this section, the basic model is extended to accommodate employee heterogeneity. The profitmaximizing firm is now concerned about job assignment, because the quality of the workforce and the allocation of employees to jobs (non-management vs. management jobs) are important for the firm's overall productivity. This implies that the firm has an additional motivation (besides incentive purposes) to promote and to lay off employees, as the two devices can be used to adjust the quality of the workforce at both hierarchical levels. ${ }^{9}$

The job-assignment model is used for two purposes. First, it is shown that sorting and selection considerations lead to the observed incentive mix. Second, the model is utilized to characterize the career path of individual employees. This proves to be useful for testing the model's predictions.

\subsection{The observed incentive mix}

Potential employees are heterogeneous. There are good employees $(G)$, with high ability, and bad ones $(B)$, with low ability. The good employees are more likely to produce a high output, as compared with the bad employees, i.e., $\theta_{G}>\theta_{B}$. However, neither the firm nor the employee is able to observe the ability of the employee. Consequently, employees (both good- and bad-ability ones) face a single outside option, providing utility $\bar{U} \cdot{ }^{10}$

The firm's external labor market consists of a proportion $\mu$ of high-ability individuals. Since the firm can use promotions and layoffs to sort and select employees in the first period, second period employee composition can differ from the composition in the external labor market. For this reason, the proportion of high-ability types in the second period at the non-management level of the firm is denoted by $\mu_{F}$, and the proportion of high-ability types at the management level is denoted by $\mu_{M}$.

Furthermore, we assume that employee quality affects production in the second period. Both managerial $(M)$ and employee $(F)$ output is assumed to depend on workforce quality: $\mu_{M}$ and $\mu_{F}$

\footnotetext{
${ }^{9}$ Furthermore, we continue to assume that sorting is based on performance in the job assigment model. The assumption is without the loss of generailty as discussed in the appendix.

${ }^{10}$ Mutually unknown ability can be thought of modeling fresh college graduates entering a firm. The graduates might not have significant information advantage, because they do not know the actual work environment. Nevertheless, as it is discussed later, the information structure provides a promising avenue for future research.
} 
respectively. The output functions are assumed to be twice differentiable: The first derivatives are assumed to be positive: $M^{\prime}, F^{\prime}>0$ and the second derivatives negative: ${ }^{11} F^{\prime \prime}, M^{\prime \prime}<0$. Furthermore, managerial quality is assumed to be weakly more important than employee quality, formally $M(x) \geq F(x)$ and $M^{\prime}(x) \geq F^{\prime}(x): \forall x \in[0,1]$.

First, the contracting problem is outlined. As prospective employees do not know their ability, the firm is unable to write a contract to elicit self-selection ex-ante. Thus, necessarily a pooling equilibrium arises, which can be summarized as follows:

$$
\begin{gathered}
\max _{w, b, \pi_{F}, \pi_{P}} \frac{M\left(\mu_{M}\right)}{H}+\left[\theta_{B}+\mu\left(\theta_{G}-\theta_{B}\right)+\delta\right](C-b)+F\left(\mu_{F}\right)-w \\
-\left[1-\theta_{B}-\mu\left(\theta_{G}-\theta_{B}\right)-\delta\right] \pi_{F} K-\frac{K}{H}
\end{gathered}
$$

subject to ${ }^{12}$

$$
\begin{aligned}
& b+\pi_{P} U_{P}+\pi_{F} U_{F} \geq \frac{e}{\delta} \\
& w-e+\left(\theta_{B}+\mu\left(\theta_{G}-\theta_{B}\right)+\delta\right)\left[b+\pi_{P} U_{P}\right]-\left(1-\theta_{B}-\mu\left(\theta_{G}-\theta_{B}\right)-\delta\right) \pi_{F} U_{F} \geq \bar{U} \\
& \left(\theta_{B}+\mu\left(\theta_{G}-\theta_{B}\right)+\delta\right) \pi_{P} \leq \frac{1}{H} \\
& \text { non-negativity } \\
& 0 \leq w, b \\
& \pi_{F}, \pi_{P} \in[0,1]
\end{aligned}
$$$$
\text { probability }
$$

Second, managerial and employee second period equilibrium composition is determined in Lemma (2).

Lemma 2 In the second period, the equilibrium proportion of good workers $\left(\mu_{F}\right)$ in the nonmanagement level depends on the firing and promotion probabilities:

$$
\mu_{F}=\mu+\mu(1-\mu)\left(\theta_{G}-\theta_{B}\right)\left(\pi_{F}-\pi_{P}\right)
$$

Moreover, the proportion of good quality workers at the managerial level $\left(\mu_{M}\right)$ is determined as:

$$
\mu_{M}=\mu\left(\theta_{G}+\delta\right) \pi_{P} H+\mu\left(1-\pi_{P} H\left(\theta_{B}+\mu\left(\theta_{G}-\theta_{B}\right)+\delta\right)\right)
$$

Furthermore, $\mu_{F}$ increases in the firing rate.

The first term in equation (4) states that employee quality is affected by the original quality $(\mu)$. The second term summarizes the effects of on-the-job selection. In particular, it shows that employee heterogeneity affects the efficiency of the selection regime. Heterogeneity can be measured as the difference between the abilities of good and bad employees $\left(\theta_{G}-\theta_{B}\right)$, and also by the variance of the distribution of the two types $(\mu(1-\mu))$. Firing $\left(\pi_{F}\right)$ affects employee quality positively, as firing is more likely to weed out bad employees. Promotion $\left(\pi_{P}\right)$, however, decreases quality, because better employees are more likely to be promoted.

Managerial quality depends on the quality of employees promoted from the employee level and the quality of those hired from outside. The first term in (5) shows the effect of promotions.

\footnotetext{
${ }^{11}$ This corresponds to assuming that the marginal return to quality is decreasing.

${ }^{12}$ The $I C$-constraint displayed below saves on notation and it is a straightforward simplification.
} 
The second term summarizes the quality effects of hiring from outside of the firm As only wellperforming agents are promoted, employees promoted from inside are on average better than managers hired from outside of the firm.

To solve the model notice again, that the promotion constraint $(P)$ is binding in equilibrium. The firm would like to promote as many well-performing employees as possible to increase either firm profit or employee well-being as in the basic model. Furthermore, job assignment considerations are also calling for promoting high performers instead of hiring untested outsiders into management. Promoting high-output employees improves on the equilibrium composition of the managerial rank through equation (5) in Lemma (2). On the other hand, the increased promotions decrease employee composition by equation (4). However, the net effect of promoting high performers is positive, because second period managerial quality is more important than employee quality: $M(x)>F(x)$ and $M^{\prime}(x) \geq F^{\prime}(x): \forall x \in[0,1] .$. In sum, ports of entry prevail also in the job assuagement model.

Furthermore, if the observed incentive mix prevails, then again the $I R$ - and $I C$-constraints must bind. The logic is the same as in the basic model.

Consequently, the observed incentive mix can only arise if all the three constraints are binding. Assume for now and verify later, that the observed incentive mix can arise. Given the binding constraints, the profit function can be expressed as a function of the firing parameter $\left(\pi_{F}\right)$. The profit maximizing first order condition with respect to $\pi_{F}$ can be expressed as:

$$
\frac{\partial F}{\partial \mu_{F}} \mu(1-\mu)\left(\theta_{G}-\theta_{B}\right)=\left[1-\theta_{B}-\mu\left(\theta_{G}-\theta_{B}\right)-\delta\right]\left(U_{F}+K\right)
$$

The left hand side of (6) summarizes the gains from firing. Gains from firing are indirect and stem from improved employee quality in the second period. The term $\frac{\partial F}{\partial \mu_{F}}>0$ shows that this indirect effect is positive. The right hand side of equation (6) summarizes the costs of firing. The term shows that the higher the expected level of firing, the higher the firm's costs are. First, employees need higher compensation to join the workforce in order to offset expected job search costs. Second, the firm incurs higher training costs, because of the increased turnover.

The first order condition shows that in the job assignment model firing is not set necessarily to zero. The observed incentive mix arises in the following case. First, the implied optimal firing rate by equation (6) and the corresponding second order condition is on the $(0,1]$ interval. ${ }^{13}$ The condition is satisfied, if the left hand side of the first order condition exceeds the right hand side at some $\pi_{F} \in(0,1]$ value. Remember, that promotion is positive by the binding $\mathrm{P}$ constraint. Second, the firm pays positive bonuses only if promotion and firing does not provide strong enough incentives. Third, the firm pays positive wages only if the promotions, firing and bonuses do not compensate for the outside job offer. Lemma (3) summarizes when the observed incentive mix can arise.

Lemma 3 In the job-assignment model an observed incentive mix of fixed wages, bonuses, promotions, and firing arises in equilibrium, if the following three conditions are satisfied. First, $\pi_{F}^{*}$ implied by (6) is strictly positive. Second, promotions implied by binding P:

$$
\pi_{P}^{*}=\frac{1}{H\left(\theta_{B}+\mu\left(\theta_{G}-\theta_{B}\right)+\delta\right)}
$$

\footnotetext{
${ }^{13}$ Note that the second derivates are necessarily negative (as $F^{\prime \prime}<0$ ), thus the first order condition suffices for the analysis.
} 
and $\pi_{F}^{*}$ does not provide enough incentives, so positive bonuses $\left(b^{*}\right)$ are needed:

$$
b^{*}=\frac{e}{\delta}-\pi_{P}^{*} U_{P}-\pi_{F}^{*} U_{F}>0
$$

Third, with $\pi_{P}^{*}, \pi_{F}^{*}, b^{*}$ positive fixed wages $\left(w^{*}\right)$ are needed for employees to accept the contract

$$
w^{*}=\bar{U}-\left(\theta_{B}+\mu\left(\theta_{G}-\theta_{B}\right)\right)\left[b^{*}+\pi_{P}^{*} U_{P}\right]+\left(1-\theta_{B}-\mu\left(\theta_{G}-\theta_{B}\right)\right) \pi_{F}^{*} U_{F}>0
$$

The results in Lemma (3) is explicit about the hierarchy of incentives. In the job assignment model, promotions and firings are used first. ${ }^{14}$ Second, remaining incentives are provided through bonuses. Finally, wages are used to make the employee accept the firm's offer.

\subsection{Characterizing employee careers}

In the above discussion, it is established that in a firm where the optimal contract involves paying an incentive mix, composition and allocation of the workforce is important for profit maximization. We used Lemma (2) to establish the relation between the offered incentives, in particular firing and the composition of the workforce. Lemma (2), however, is silent about the consequences of these policies for individual workers.

Promotions and layoffs affect the firm's selection scheme. As these decisions are based on employee performance, they have different consequences for high- and low-ability employees. In particular, for the high-ability worker, the probability of being fired in any given period is $\left(1-\theta_{G}-\delta\right) \pi_{F}$, and for the low-ability worker, the probability is $\left(1-\theta_{B}-\delta\right) \pi_{F}$. Hence, it is more likely that the bad worker loses his job. By the same logic, good workers are more likely to be promoted, as $\left(\theta_{G}+\delta\right) \pi_{P}>\left(\theta_{B}+\delta\right) \pi_{P}$.

This allows for investigating the effects of the optimal contract on selection in rank and tenure. Selection on rank is always positive, as well-performing agents, who are more likely to be of good quality than the average employee, are promoted. Selection on tenure depends upon the relative strength of firing and promotion. Firing weeds out the low-ability employees, whereas promotions weed out the high-ability employees from the non-management ranks. These results are formalized in Lemma (4).

Lemma 4 The selection process in the firm is positive in rank (conditional on tenure). Selection on tenure (conditional on rank) is negative if

$$
\pi_{P}>\pi_{F}
$$

and positive if

$$
\pi_{P}<\pi_{F}
$$

Previous studies have analyzed the selection mechanism Medoff and Abraham [1980, 1981], Lazear [1992], Gibbs [1995], and Gibbons and Waldman [1999b]. For instance, based on a series of empirical findings, Medoff and Abraham $[1980,1981]$ write "... the negative within-grade-level correlation which we suspect exists between experience and ability." Lazear [1992] continues this

\footnotetext{
${ }^{14}$ For the sake of completeness note, that if there are no bonus payments (the IC-constraint is satisfied with slack in equilibrium), then not equation (6) will determine optimal firing.
} 
discussion, arguing that "Individuals who remain on the job longer, do worse than those who are promoted out early. Wages actually decline with job tenure, probably reflecting the fall in the average worker's quality with length of time in the job." In the context of our model, it is clear that if only selection due to promotions is at work, the quality of the workforce that is passed over for promotion will decline with tenure. The optimal contract, however, shows that the firm has incentives to lay off a proportion of the low-performing workers each period. That this behavior affects the selection process is a point that is often missed in the literature. Gibbs [1995] comes closest to this point, and concludes that “... employees are continuously selected out through promotions, demotions, or exits. Because of these selection effects, ability of the group should decline with tenure..."

From this discussion, it is clear that negative selection on tenure is a possibility, but not the rule. If the firing probability exceeds the promotion probability, the selection scheme in tenure shifts from negative to positive. As it will turn out in the empirical analysis conducted below, our firm has a positive selection on tenure (conditional on rank), which provides a counterexample to the earlier conclusions drawn about negative within-rank employee selection.

\subsection{Comparative statics}

Employee sorting is important, not only for the observed incentive mix to be an optimal contract, but also because the selection regime predicts the outcome of other key variables in the firm. This makes it interesting to understand what components in the underlying market structure will lead to a particular selection regime.

Examining the first order condition (6) provides interesting comparative statics. On the one hand, variables on the left hand side in general contribute to more firing. First, the stronger long run employee output $(F)$ responds to quality improvements, the more the firm is interested in improving the quality of its workforce. Second, employee heterogeneity also increases the firing rate. Employee heterogeneity can be measured as the variance of different types, $\mu(1-\mu)$, where larger heterogeneity corresponds to $\mu$ values closer to $1 / 2$ or a 50-50 split. Employee heterogeneity can also be measured by the quality difference between the high- and the low-ability individuals $\left(\theta_{G}-\theta_{B}\right)$. Both measures of heterogeneity increase the indirect gains from firing. Intuitively, the more heterogeneous newly hired employees are, the more is to gain from on-the-job sorting. ${ }^{15}$

On the other hand, variables on the right hand side of (6) decrease firing. The social costs of firing $\left(U_{F}\right.$ and $\left.K\right)$ have a negative effect on the firing rate. Hence, it reduces the likelihood of positive selection. This follows from the fact that the firm shoulders all the costs of turnover in equilibrium. A reduction of these costs, however, implies that the firm can rely more on firing.

This discussion indicates that the value of production, employee quality and variation in the cost of firing, are important determinants for the firm's choice of selection scheme. Variation in these parameters across time, sectors, and economies will be useful predictors for the type of selection that will be observed in firms.

\footnotetext{
${ }^{15}$ Note, that the heterogeneity measure $\mu(1-\mu)\left(\theta_{G}-\theta_{B}\right)$ is the first derivative of the second period employee quality $\left(\mu_{F}\right)$ with respect to the firing parameter $\left(\pi_{F}\right)$.
} 


\subsection{Empirical predictions}

The model can be interpreted as capturing the selection and incentive procedure ongoing in the firm as the model identifies the criteria for positive and negative selection on tenure (conditional on rank). Selection further allows for the formulation of predictions about other key variables. Having this interpretation in mind, the model provides two main additional empirical predictions besides producing the observed incentive mix.

First, bonus payments can be used to test for selection in the firm. A basic assumption of the model is that the firm rewards high performance with bonuses. Thus, the firm's selection scheme has direct consequences for the way bonuses are paid to the individuals. For instance, in the positive selection case, the probability of being high-ability is increasing in tenure and rank, and thus the probability of receiving bonuses is also increasing in tenure. ${ }^{16}$ If the firm has a negative selection, the probability of receiving bonuses would decrease in tenure.

Second, selection also has implications for the evolution of promotions and layoffs in tenure. Given that promotions are conditioned on high output, with positive selection promotions are predicted to increase in tenure. Similarly, with positive selection layoffs are expected to decrease in tenure.

These predictions are outlined below, and they will be tested empirically in the following sections. The predictions are derived directly from the basic assumptions of the model and its lemmas, so they are not proven formally again.

Predictions 1 (Sorting) Sorting based on performance is a necessary condition for the observed incentive-mix of fixed wages, bonuses, promotions, and firing to be an optimal contract.

Prediction 2 (Selection) The firm has a positive selection on rank (conditional on tenure). Furthermore, it has a positive selection on tenure (conditional on rank), if and only if $\pi_{F}>\pi_{P}$. Otherwise, it has a negative selection on tenure.

Prediction 3 (Bonus) The probability of receiving a bonus depends positively upon the employees' ability. Thus, with ports of entry, the likelihood of receiving a bonus increases in rank. Furthermore, the probability of receiving a bonus is increasing in tenure, if and only if the firm has a positive selection on tenure.

Prediction 4 (Promotion) The likelihood of being promoted depends positively,upon the employees' ability. Thus, the probability of being promoted increases in tenure, if and only if the firm has a positive selection on tenure.

Prediction 5 (Firing) The likelihood of being fired depends negatively upon the employees' ability. Thus, the probability of being fired declines in tenure, if and only if the firm has a positive selection on tenure.

\section{Data}

Four years of monthly personnel records from the main production site of an international pharmaceutical company are used in the empirical analysis. ${ }^{17}$ Average full-time employment in the

\footnotetext{
${ }^{16}$ From this prediction it follows that positve selection could imply an increasing earnings profile.

${ }^{17}$ The study is conducted on monthly observations, in contrast to yearly observations. The main motivation for doing this is that the timing of events within a year proves to be important. In the regression results presented below, a "correction" for the use of high-frequency data is made by using clustered standard errors.
} 
firm over the period 1997 to 2000 is 5055 persons. ${ }^{18}$ These workers are distributed across four hierarchical levels, ranging from CEO to non-management see Figure 2. The share of management workers in the firm is 4.75 percent, on average, over the four years.

The analysis given below uses only those individuals who participate in the performance-pay system, i.e., the employees who, besides their base salary, can get a bonus, given sufficiently high performance evaluations. The distinction between strictly fixed paid employees, and employees having bonus options, can be made by looking at the worker's job category. This exercise reveals that the group of fixed-paid employees constitutes 38.66 percent of the workforce, and that it mainly consists of production workers.

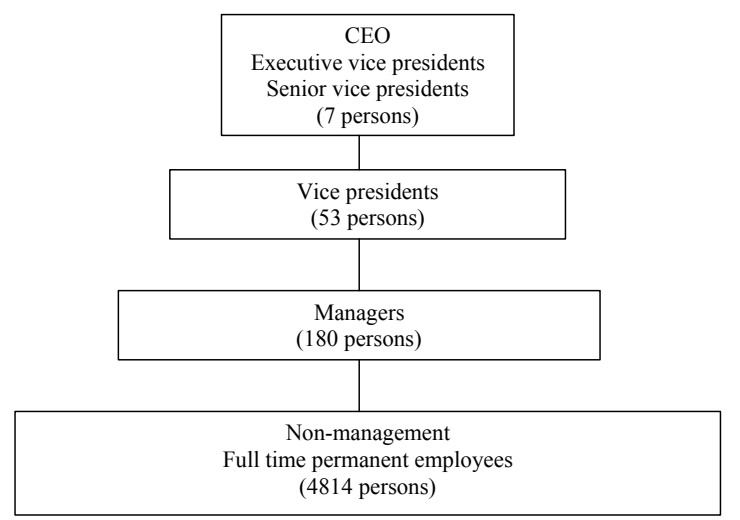

Figure 2: The hierarchy of the firm, 1997 to 2000

The characteristics of the employees calculated from the monthly employee-based observations are presented in the second and third columns of Table 2. On average, the employees included in the analysis, i.e., those who participate in the performance-pay system (column 3), have 8.73 years of tenure. The same group of individuals consists of 60.80 percent women, and the average age is 39.23 years.

The level of education in the firm is high. In fact, 22.0 percent of the employees have at least a master's degree, and 11.6 percent have a degree that corresponds to a bachelor's degree in duration. Only 12.6 percent of the labor force is unskilled. ${ }^{19}$ There are three reasons why this structure is observed. First, the firm is operating in an industry where product development is essential for survival. Hence, a large proportion of the workforce is engaged in research and development. Second, production is highly automated, suggesting that low-skilled labor has been substituted by capital. Finally, in order to comply with the regulations from the Food and Drug Administration (FDA), extensive quality-control programs are implemented, which require skilled labor.

\footnotetext{
${ }^{18}$ The analysis is focused on permanent full-time employment, which corresponds to 92.66 percent of all individuals employed on the production site.

${ }^{19}$ Information on education is missing for 8.21 percent of the employees. However, for the group of employees receiving performance pay, only 2.84 percent have missing information on education.
} 


\begin{tabular}{lcc}
\hline \hline & \multicolumn{2}{c}{$\begin{array}{c}\text { Mean } \\
\text { (standard deviations) }\end{array}$} \\
\cline { 2 - 3 } & $\begin{array}{c}\text { All employees } \\
\text { Observations }=237,539\end{array}$ & $\begin{array}{c}\text { Employees participating in } \\
\text { the performance pay system } \\
\text { Observations }=145,717\end{array}$ \\
\hline Age & $\begin{array}{c}(8.353 \\
\text { Gender }\end{array}$ & $\begin{array}{c}8.2261 \\
\text { Gender }\end{array}$ \\
Unskilled & 0.568 & 0.608 \\
Skilled worker & 0.126 & 0.035 \\
Short theoretical education & 0.269 & 0.159 \\
Bachelor degree & 0.192 & 0.282 \\
Masters or PhD degree & 0.116 & 0.173 \\
Tenure 2 years or less & 0.220 & 0.351 \\
Tenure 3 to 5 years & 0.202 & 0.188 \\
Tenure 5 to 10 years & 0.159 & 0.154 \\
Tenure 10 to 15 years & 0.309 & 0.287 \\
Tenure 15 to 25 years & 0.165 & 0.186 \\
Tenure 25 years or above & 0.133 & 0.141 \\
\hline \hline
\end{tabular}

Table 2: Descriptive statistics

\subsection{The empirical contract, and the theoretical assumptions}

According to the firm's official remuneration principles, it offers wages to the employee such that: "The base salary is a competitive pay for job function, responsibilities and competencies." The data provide evidence for the fact that this principle is taken seriously. For instance, a preliminary analysis of the fixed-wage component reveals that a set of individual characteristics and information about the employee's job category predicts wages precisely $\left(R^{2}=0.865\right)$.

Individuals are rewarded for actual performance through a bonus system. The allocation of bonuses fulfills the criteria that: "The principles, criteria and targets that will lead to bonus payments should be known by the relevant employee subgroup." The size of the bonus pool varies across the different employee subgroups, and constitutes 2.5 to 4 percent of the wage sum for non-management workers, and 8 percent for non-executive managers. ${ }^{20}$ The bonus system is widespread, and according to the data, 24 percent of workers in non-management receive bonus payments in a given year. The numbers are closer to 75 and 80 percent for managers and vice-presidents, respectively.

The institutional settings impose no restriction on who to fire, and the firm seems to use firing frequently. The firm's yearly separation rate is 10.96 percent. The turnover is costly for the firm, but nevertheless, 12.64 percent of all separations are initiated by the firm through layoffs. The separation rate for the employees participating in the performance-pay system is 6.64 percent.

\footnotetext{
${ }^{20}$ The subsequent analysis is based on non-management employees, managers, and vice-presidents. The executive management is omitted, due to lack of data.
} 
Of these, 19.46 (!) percent are initiated by the firm. Thus, firing is a significant component of the observed incentive mix.

There are two motivations for laying off workers. First, the firm's official wage strategy is to: "Offer attractive salary and employment conditions" in order to "attract, develop and retain qualified employees." Given the "attractive" wages, the firm can use the threat of a layoff to motivate the workers. ${ }^{21}$ Second, the layoffs serve as a sorting device, where a proportion of the employees with low performers are forced to separate from the firm in each period. Hence, in a pooling equilibrium where both high- and low-ability workers are employed by the firm, layoffs can be used to control the worker composition.

Finally, the firm has ports of entry as the binding $P$ constraint implies. This claim is based on the observation that 98.22 percent of the employees are hired into the lowest hierarchical level. One implication of ports of entry is that management vacancies are filled with incumbent employees. Naturally this policy serves both sorting and incentive purposes. The wage premium (unconditional on human capital) associated with a promotion from non-management and into lower-and middle-management are 52.46 percent and 85.65 percent, respectively.

In the presentation of the firm, it becomes clear that the contract offered to the workers is highly complex in nature. First, the firm pays fixed wages to all workers who accept the contract, unconditional on performance. Second, 62 percent of the employees can be rewarded for performance through a bonus system. Third, even though turnover is costly for the firm, a significant part of separations is firm-initiated, i.e., layoffs. Finally, the firm has ports of entry, which implies that promotions to higher-level jobs take place (mainly) from the pool of incumbent employees. In sum, the data describes a contract that contains four incentive parameters: $w, b$, $\pi_{P}$, and $\pi_{F}$.

\section{$5 \quad$ Empirical analysis}

The predictions stated above will be tested empirically in this section. A first goal is to establish that the firm is sorting its employees. According to the job-assignment model, this is a necessary condition for the observed incentive mix to be an optimal contract. Secondly, the firm's selection scheme is identified to be positive in rank and tenure. This information provides predictions about other key variables in the firm, such as earnings growth, bonus payments, firing, and promotions. For this reason, a test of the model's broader predictions will be conducted in the final part of the analysis.

Prediction (1) stated that employee sorting based on performance is a necessary condition for the incentive mix to be an optimal contract. Preliminary evidence for sorting is found in the description of the empirical contract where it is established that layoffs and promotions are common in the firm, i.e., $\pi_{P}, \pi_{F}>0$. The presence of layoffs and promotions are necessary conditions for sorting, but are not sufficient in the sense that random decisions would produce no sorting. Thus, a first test for the presence of sorting is to investigate whether the firm makes random decisions, or whether it bases its decisions on information about the employee's revealed performance (and thus on expected ability). The measure of performance that will be used in

\footnotetext{
${ }^{21}$ All workers in the firm have defined contribution pension plans, hence a layoff will not change the value of the current pension account. In other firms, where workers have defined benefit pension plans, the costs of a layoff in terms of lost pension may be significant. This effect could potentially create large incentives in other firms.
} 
the analysis is bonus payments. ${ }^{22}$

To establish that the firm is sorting, a multinomial logit model is estimated. In the model, the individual is facing the three options: stay within rank, promotion, and, layoff. ${ }^{23}$ The point estimates of a multinomial logit are difficult to interpret, and, hence, the results of the model are evaluated using its predictions. ${ }^{24}$ The effect of a bonus payment on the transition probabilities is presented in Table 3. A person who receives a bonus payment (i.e., who's had high performance) has a 0.136 percent chance of being promoted in a given month, while the layoff probability is as low as 0.025 percent. In contrast, a person who did not receive a bonus payment (low performance) has little chance of being promoted, and faces a 0.241 percent risk of being laid off from the firm in any given month. ${ }^{25}$ Hence, a bonus payment increases the promotion probability, with 0.072 , percent and reduces the firing probability, with 0.216 percent. This is clear evidence for the fact that the firing and promotion decisions are based on employee performance, meaning the firm is consciously sorting its employees.

\begin{tabular}{lccc}
\hline \hline & \multicolumn{3}{c}{ Destinations } \\
\cline { 2 - 4 } & Promotion & Layoff & Stay within rank \\
\hline $\begin{array}{l}\text { Average transition probability } \\
\text { [sample means in brackets] }\end{array}$ & $0.112 \%$ & $0.116 \%$ & $99.772 \%$ \\
& {$[0.112 \%]$} & {$[0.116 \%]$} & {$[99.772 \%]$} \\
$\begin{array}{l}\text { Average transition probability } \\
\text { given bonus is received. }\end{array}$ & $0.136 \%$ & $0.025 \%$ & \\
$\begin{array}{l}\text { Average transition probability } \\
\text { given no bonus is received. }\end{array}$ & $0.064 \%$ & $0.241 \%$ \\
$\begin{array}{l}\text { Change in probability due to } \\
\text { bonus }\end{array}$ & $0.072 \%$ & $-0.216 \%$ \\
\hline $\begin{array}{l}\text { Note: The predictions are based on a regression with } 96,639 \text { observations. See the appendix for the full } \\
\text { regression results. }\end{array}$
\end{tabular}

Table 3: Predicted monthly transitions

Prediction (2) gave conditions when sorting is positive or negative. They can be tested from the empirical evidence presented in Table 3. First, the results reveal that high-performance employees are relatively more likely to be promoted. Since high-ability individuals are more likely to have a high performance, this finding provides evidence for a selection scheme that is positive on rank. Second, the conditional layoff probability $\left(\pi_{F}=0.241\right.$ percent) exceeds the conditional promotion probability $\left(\pi_{P}=0.136\right.$ percent). According to Lemma (4), this implies a positive selection on tenure.

Moreover, the positive selection might be even stronger than shown by these numbers, due to a bias in the layoff data. A bias arises in the case where the firm is signaling to the worker that the employment relation will end in the near future. This signal will make the worker look for alternative employment, which may be obtained before the firm terminates the match.

\footnotetext{
${ }^{22}$ Bonuses paid to the individual during the preceeding 12 months are used as an indicator for performance, i.e., if the individual received a bonus payment in the period, he or she must have had high performance.

${ }^{23}$ It should be noted that the individuals who separate for natural causes, such as retirement or death, and the individuals who leave the firm for a new job have been deleted from the sample.

${ }^{24}$ The full regression results of the multinomial logit can be seen in Table 8 in the appendix.

${ }^{25}$ The unconditional yearly promotion probability in the firm is 1.34 percent. In comparison, Lazear (1992) observes a yearly promotion probability close to 2 percent.
} 
From conversations with the firm, we have reason to believe that this procedure is common. The implication is that the layoffs observed in the firm only constitute a lower bound on the separations, that, in reality are layoffs. ${ }^{26}$

Prediction (3) focuses on bonus payments. Since the likelihood of receiving bonuses depends upon employee ability, the selection scheme used by the firm, and the probability of receiving a bonus are closely linked. One consequence of the positive selection identified in the firm is that more able workers in general will have longer tenure, and will be assigned to higher-rank jobs. Hence, with positive selection, employees who have longer job tenure and who are located at higher ranks (conditional on tenure) will be more likely to receive bonus payments. This observation provides a first test for the model's broader predictions.

\begin{tabular}{|c|c|c|c|}
\hline & $\begin{array}{c}(1) \\
\text { Logit model }\end{array}$ & $\begin{array}{c}(2) \\
\text { Logit model }\end{array}$ & $\begin{array}{c}(3) \\
\text { Fixed-effects } \\
\text { Logit model }\end{array}$ \\
\hline Constant & $\begin{array}{l}-3.352 \\
(0.585)\end{array}$ & $\begin{array}{l}-3.804 \\
(0.608)\end{array}$ & - \\
\hline Tenure 2 years or less & - & - & - \\
\hline Tenure 3 to 5 years & $\begin{array}{c}0.279 \\
(0.080)\end{array}$ & $\begin{array}{c}0.277 \\
(0.080)\end{array}$ & $\begin{array}{l}-0.076 \\
(0.139)\end{array}$ \\
\hline Tenure 5 to 10 years & $\begin{array}{c}0.361 \\
(0.079)\end{array}$ & $\begin{array}{c}0.370 \\
(0.079)\end{array}$ & $\begin{array}{l}-0.351 \\
(0.208)\end{array}$ \\
\hline Tenure 10 to 15 years & $\begin{array}{c}0.520 \\
(0.090)\end{array}$ & $\begin{array}{c}0.524 \\
(0.090)\end{array}$ & $\begin{array}{c}-0.476 \\
(0.298)\end{array}$ \\
\hline Tenure 15 to 25 years & $\begin{array}{c}0.455 \\
(0.102)\end{array}$ & $\begin{array}{c}0.476 \\
(0.102)\end{array}$ & $\begin{array}{l}-0.393 \\
(0.407)\end{array}$ \\
\hline Tenure 25 years or above & $\begin{array}{c}0.528 \\
(0.146)\end{array}$ & $\begin{array}{c}0.550 \\
(0.145)\end{array}$ & $\begin{array}{c}0.429 \\
(0.660)\end{array}$ \\
\hline Non-management & - & - & - \\
\hline Managers & $\begin{array}{c}0.675 \\
(0.188)\end{array}$ & $\begin{array}{c}0.718 \\
(0.183)\end{array}$ & $\begin{array}{c}0.629 \\
(0.433)\end{array}$ \\
\hline Vice presidents & $\begin{array}{l}1.676 \\
(0.384)\end{array}$ & $\begin{array}{c}1.665 \\
(0.383)\end{array}$ & $\begin{array}{c}0.719 \\
(1.117)\end{array}$ \\
\hline Unskilled & & - & \\
\hline Skilled worker & & $\begin{array}{c}0.383 \\
(0.158)\end{array}$ & \\
\hline Short theoretical education & & $\begin{array}{c}0.442 \\
(0.156)\end{array}$ & \\
\hline Bachelor degree & & $\begin{array}{c}0.401 \\
(0.163)\end{array}$ & \\
\hline Masters or $\mathrm{PhD}$ degree & & $\begin{array}{c}0.622 \\
(0.185)\end{array}$ & \\
\hline Demographic variables & YES & YES & YES \\
\hline Job category & YES & YES & YES \\
\hline Time dummies & YES & YES & YES \\
\hline $\begin{array}{l}\text { Log likelihood } \\
\text { \# observations }\end{array}$ & $\begin{array}{l}-5964 \\
10,801\end{array}$ & $\begin{array}{l}-5954 \\
10,801\end{array}$ & $\begin{array}{l}-1882 \\
10,801\end{array}$ \\
\hline
\end{tabular}

Table 4: Logit regression for bonus payments

\footnotetext{
${ }^{26}$ For the sake of completeness, we remark here that selection might get weakened by employee-initiated turnover. High-ability employees, who are underappreciated, might leave the firm for better offers. This, however, does not seem to be a serious problem, as it would require outside firms to have systematically better information than the current employer. It seems, then, that employee-initiated endogenous turnover (if any) is about terminating a bad match, rather than about ability.
} 
Table 4 presents logit regressions for the probability of having received a bonus payment during the preceding year. In the first model, tenure, rank and demographic information (gender, age and age squared) are included as explanatory variables, together with dummies for job category and time. As expected, both tenure and rank have significantly positive effects on the probability of receiving bonuses.

In model 2, information on education is added. The positive relation between educational attainment and ability, and the increased production capacity of educated workers, implies that workers with higher levels of schooling will be more likely to receive bonus payments see Becker [1964]. This result is confirmed by the data. Important for the analysis, however, is to note that the positive effects of tenure and rank on the probability of receiving bonuses survive in model 2. This indicates that ability is signaled only partially through education. Thus, sorting and selection considerations are important, even though the level of formal schooling is observed. ${ }^{27}$

An additional test for the relation between tenure and bonus is conducted by estimating a model similar to model 2 in Table 4, with the tenure categories substituted for yearly tenure dummies (detailed results are not shown). ${ }^{28}$ Figure 3 illustrates the cross-sectional effect of tenure on the likelihood of receiving a bonus for the first 25 years of tenure. In accordance with the predictions from positive sorting, the effect is increasing. Thus, the steady increase in the likelihood of receiving bonuses during the first many years of employment reflects that sorting and selection are integrated parts of the firm's policy.

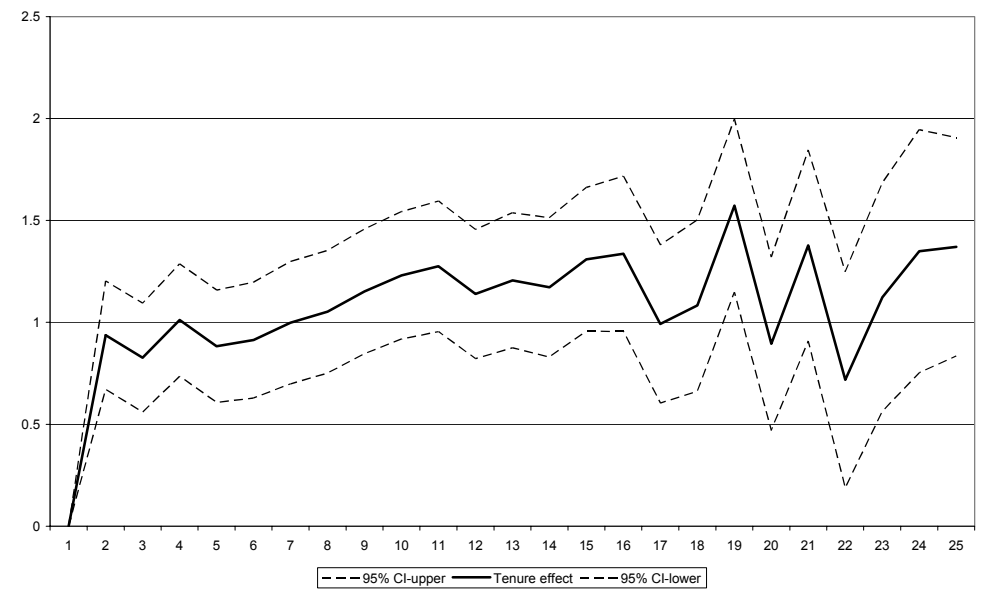

Figure 3: Tenure-effect on the likelihood of receiving bonus payments

Finally, the cross-sectional relation between the probability of getting a bonus and tenure could arise if a bonus is paid for tenure, and not for performance, as we argue in the model. For this reason, a fixed-effects model, where the individual's ability is "conditioned out" is estimated, model 3 in Table 4 . In this model, the tenure effect is insignificant, reflecting that ability, and

\footnotetext{
${ }^{27}$ The tenure-effect identified in Table 4 could, in principle, be driven by the fact that managerial employees, who, in general, have longer tenure, are more likely to recieve bonuses. For this reason, model (3) has been estimated for the non-management employees only. The results show that the tenure effect is robust.

${ }^{28}$ The maximum level of tenure in the firm is 44 years, but less than 3.25 percent of the employees have a tenure above 25 years, causing large standard errors on the point estimates of the tenure dummies exceeding the 25 th year.
} 
not tenure, determines the probability of receiving bonus payments. This finding allows us to conclude that the increasing cross-sectional bonus-tenure profile observed in the data is driven by positive selection. ${ }^{29}$

Predictions (4) and (5) state the model's predictions on promotions and layoffs. The positive selection identified in the firm implies that non-management employees with longer tenure are of higher average ability than more recently hired individuals. Above it is argued that this will lead to higher average performance of the tenured employees, and consequently to a higher probability of promotion. Since the tenure-effect on promotions is working through the performance variable, taking the employees performance into account would remove the tenure-effect, allowing only performance to have a significant effect on promotions. A similar argument goes for the layoff probability. The expected higher average performance of the high-tenured individuals will at first create a negative relation between layoffs and tenure. However, conditional on performance, tenure will become insignificant.

These hypotheses are tested empirically using logit models for the probability of being promoted and laid off. The results are presented in Table 5. A first observation is that promotions and layoffs are very difficult to predict if information on performance is missing. In model 1, where the probability of a promotion is estimated unconditional of employee performance, the expected tenure-effect, is absent. Instead, there is a weak indication that skills are important for the promotion process, since individuals with a master's or a Ph.D. degree have a marginally higher probability of being promoted than do unskilled workers. This result, however, is washed out, when conditioning on performance (model 2), indicating that education is important for the promotion process, but only through its positive effect on the likelihood of getting bonuses. This leads to the conclusion that the firm only promotes workers who have shown persistent high-performance, and that the direct effect of tenure on promotions is too weak to be identified in the present firm.

The first layoff regression (model 3) in Table 5 shows a pattern similar to the promotionregression, namely, that layoffs are difficult to predict if information on performance is absent. In model 4 , it is reestablished that information on bonus payments has a highly significant effect on the decision about who to lay off. Also, there is an indication that layoffs are rare for newly hired individuals, i.e., employees with tenure less than two years.

An additional point that arises from the results is that some employee subgroups (defined by education) are more likely to be laid off than others. This result seems to stay, even when performance is taken into account. This empirical result, however, may simply be an artifact of missing lay-off information. The indicator of layoffs observed in the data only reflects a lower bound on the real extent of layoffs (as discussed above). In particular, the empirical result observed will emerge if the firm is more likely to signal that an employment match is about to

\footnotetext{
${ }^{29}$ The models presented in the table provide detailed evidence of the tenure effect on bonus payments due to the inclusion of the six tenure categories. The details come at the cost, however, that the standard errors for each tenure group becomes fairly high, and may question whether the groups are significantly different or not. To anticipate this criticism, the appendix (Table 8) provides estimates of models similar to those presented in Table 4 , but where the category dummies are substituted for a linear tenure effect. These regressions show that the tenure-effect is highly significant and positive in the cross-sectional models, and insignificant in the fixed-effects models. Hence, they resemble the results of the table. The regressions also show that these results are not driven by the very low probability of getting bonus payments for newly hired employees (whose tenure is less than one or two years).
} 
end, to some employee subgroups relative to others. In this particular case, it is explained if skilled workers (typically production workers) are more likely to get this information than other employee subgroups. This can be due to increased sensitivity of information handled by more educated employees. Given the available data, we can only speculate about these matters.

\begin{tabular}{|c|c|c|c|c|}
\hline & $\begin{array}{c}\text { Promotion } \\
\text { regression } \\
\text { (1) }\end{array}$ & $\begin{array}{l}\text { Promotion } \\
\text { regression } \\
\text { (2) }\end{array}$ & $\begin{array}{c}\text { Layoff } \\
\text { regression } \\
\text { (3) }\end{array}$ & $\begin{array}{c}\text { Layoff } \\
\text { regression } \\
(4)\end{array}$ \\
\hline Constant & $\begin{array}{c}-10.591 \\
(2.971)\end{array}$ & $\begin{array}{c}-10.348 \\
(2.979)\end{array}$ & $\begin{array}{l}-7.322 \\
(2.604)\end{array}$ & $\begin{array}{c}-8.652 \\
(2.660)\end{array}$ \\
\hline Bonus payment & & $\begin{array}{c}0.762 \\
(0.246)\end{array}$ & & $\begin{array}{l}-2.303 \\
(0.289)\end{array}$ \\
\hline Tenure 2 years or less & - & - & - & - \\
\hline Tenure 3 to 5 years & $\begin{array}{c}0.143 \\
(0.320)\end{array}$ & $\begin{array}{c}0.061 \\
(0.317)\end{array}$ & $\begin{array}{c}0.499 \\
(0.499)\end{array}$ & $\begin{array}{c}0.657 \\
(0.501)\end{array}$ \\
\hline Tenure 5 to 10 years & $\begin{array}{c}0.329 \\
(0.311)\end{array}$ & $\begin{array}{c}0.233 \\
(0.308)\end{array}$ & $\begin{array}{c}0.589 \\
(0.457)\end{array}$ & $\begin{array}{c}0.770 \\
(0.461)\end{array}$ \\
\hline Tenure 10 to 15 years & $\begin{array}{c}0.264 \\
(0.377)\end{array}$ & $\begin{array}{c}0.156 \\
(0.376)\end{array}$ & $\begin{array}{c}0.765 \\
(0.481)\end{array}$ & $\begin{array}{c}0.942 \\
(0.482)\end{array}$ \\
\hline Tenure 15 to 25 years & $\begin{array}{c}0.016 \\
(0.557)\end{array}$ & $\begin{array}{l}-0.104 \\
(0.553)\end{array}$ & $\begin{array}{c}0.662 \\
(0.497)\end{array}$ & $\begin{array}{c}0.833 \\
(0.495)\end{array}$ \\
\hline Tenure 25 years or above & $\begin{array}{c}0.142 \\
(0.863)\end{array}$ & $\begin{array}{c}0.021 \\
(0.866)\end{array}$ & $\begin{array}{c}0.638 \\
(0.571)\end{array}$ & $\begin{array}{c}0.743 \\
(0.562)\end{array}$ \\
\hline Unskilled & - & - & - & - \\
\hline Skilled worker & $\begin{array}{l}-0.936 \\
(1.230)\end{array}$ & $\begin{array}{l}-0.939 \\
(1.229)\end{array}$ & $\begin{array}{l}-1.502 \\
(0.542)\end{array}$ & $\begin{array}{l}-1.444 \\
(0.542)\end{array}$ \\
\hline Short theoretical education & - & - & $\begin{array}{l}-0.476 \\
(0.429)\end{array}$ & $\begin{array}{l}-0.585 \\
(0.432)\end{array}$ \\
\hline Bachelor degree & $\begin{array}{c}1.211 \\
(1.041)\end{array}$ & $\begin{array}{c}1.080 \\
(1.043)\end{array}$ & $\begin{array}{c}0.331 \\
(0.427)\end{array}$ & $\begin{array}{c}0.698 \\
(0.428)\end{array}$ \\
\hline Masters or $\mathrm{PhD}$ degree & $\begin{array}{c}2.159 \\
(1.027)\end{array}$ & $\begin{array}{c}1.974 \\
(1.029)\end{array}$ & $\begin{array}{l}-0.368 \\
(0.428)\end{array}$ & $\begin{array}{c}0.281 \\
(0.434)\end{array}$ \\
\hline Demographic variables & YES & YES & YES & YES \\
\hline Time dummies & YES & YES & YES & YES \\
\hline Log likelihood & -749.86 & -744.54 & -768.83 & -723.03 \\
\hline \# observations & 66,655 & 66,655 & 96,639 & 96,639 \\
\hline
\end{tabular}

Table 5: Layoff and promotion regressions

In sum, the empirical evidence presented above provides evidence for the model's predictions. First, using the description of the empirical contract and the multinomial logit regression, it is established that the firm is sorting, such that high-performing employees are more likely to be promoted, and, subsequently, are less likely, to be fired. Furthermore, these results show that the firm is using a selection scheme that is positive in both tenure and rank. Using the information on sorting and selection then, the model provides prediction about other key variables. The broader predictions related to bonus payments, earnings growth, promotions, and layoffs are all supported by the data.

\section{Discussion}

In the seminal work by Gibbons and Waldman [1999a,b], they argue that: "Any single (empirical) fact may be consistent with a variety of theories, so one way to choose among theories is by 
evaluating the extent to which each is consistent with a broad pattern of (empirical) evidence." This paper has attempted to do exactly that.

As to the initial research question of how the incentive-mix observed in firms can be seen as an optimal contract, this paper focuses on the job-assignment model. Within this context, it is argued that the firm's sorting and selection concerns, and its interest in creating incentives for employees, provide the answer. This is a contribution in a theoretical sense, but according to the Gibbons and Waldman critique, the true test of the model lies in its ability to predict additional empirical findings. For this reason we conduct an empirical analysis, where evidence for sorting and selection is identified, and the model's broader predictions are tested. In general, there is a close fit between the model's predictions and the empirical evidence.

However, our model cannot predict the evolution of fixed wages. This suggests that the jobassignment model should be extended by other building blocks in a larger integrative model, as suggested in Gibbons and Waldman [1999a,b]. In the following, we discuss the empirical findings that an integrative model has to accommodate. Also, we explore possible theoretical explanations and provide suggestions for future research.

Table 6 presents a set of Mincer wage equations. In contrast to the standard case, these regressions include information on the firm's hierarchy. Thus, the results obtained reflect withinrank wage dynamics. Model 1 shows that the wage is increasing in the levels of education, tenure, and rank. Model 2 explores the effect of a bonus payment on current wages. The point-estimate shows that a bonus payment last period (which also can be interpreted as high performance) leads to significantly higher current wages. An extension of this analysis is conducted in model 3 , where information of up to three years of lagged bonus payments is included. The remarkable result reveals that lagged bonus payments are highly significant. Furthermore, they have similar effects on current wages. Hence it is not the timing, but instead the event of bonus that seems to be important.

To investigate this issue further, model 4 estimates the effect of the last two years' bonus payments on the wage, together with an interaction-effect, capturing the consequences for current wages of receiving bonuses in both years. ${ }^{30}$ The interaction-term in this regression is insignificant, reflecting that bonuses are increasing wages every time they are observed. In other words, the bonus-effect is not deflated or magnified when the employee is observed to have a persistent high performance. These empirical observations are not easily explained by the job-assignment model, but a variety of other theoretical explanations provide possible explanations. Here, on-thejob human-capital acquisition, symmetric learning, and asymmetric learning with probabilistic outside offers are discussed.

The first potential explanation for the fixed-wage dynamics is on-the-job human-capital acquisition. Gibbons and Waldman [1999a,b] show how on-the-job human-capital acquisition, in conjunction with other building-block models (job assignment and learning) can be used to explain a large set of empirical evidence. The Gibbons and Waldman model distinguishes between the employees' innate ability, which can be high or low, and effective ability, which is a function of the employees' innate ability and labor-market experience. An assumption on symmetric information and steady changes in the employees' effective ability caused by continuous growth in labormarket experience leads to fixed-wage dynamics. Thus, on-the-job human-capital acquisition

\footnotetext{
${ }^{30}$ The focus on the last two years' bonus payments is only for expositional reasons, and easily could be extended to include all three years and their interaction terms.
} 
implies a simple, upward-sloping fixed-wage scheme for all workers. On-the-job human-capital acquisition, however, cannot explain, without a stretch, the significant and positive coefficient on bonus payments, which we observe in our data.

\begin{tabular}{|c|c|c|c|c|}
\hline & (1) & (2) & (3) & (4) \\
\hline Constant & $\begin{array}{c}9.314 \\
(0.036)\end{array}$ & $\begin{array}{c}9.395 \\
(0.037)\end{array}$ & $\begin{array}{l}9.596 \\
(0.045)\end{array}$ & $\begin{array}{c}9.497 \\
(0.040)\end{array}$ \\
\hline Bonus payment last year & & $\begin{array}{c}0.023 \\
(0.002)\end{array}$ & $\begin{array}{c}0.016 \\
(0.003)\end{array}$ & $\begin{array}{c}0.021 \\
(0.003)\end{array}$ \\
\hline $\begin{array}{l}\text { Bonus payment two } \\
\text { years ago }\end{array}$ & & & $\begin{array}{c}0.012 \\
(0.003)\end{array}$ & $\begin{array}{c}0.025 \\
(0.004)\end{array}$ \\
\hline $\begin{array}{l}\text { Bonus payment three } \\
\text { years ago }\end{array}$ & & & $\begin{array}{c}0.018 \\
(0.003)\end{array}$ & \\
\hline $\begin{array}{l}\text { Bonus payment last year } \\
\text { and two years ago }\end{array}$ & & & & $\begin{array}{l}-0.008 \\
(0.005)\end{array}$ \\
\hline Tenure 2 years or less & - & - & & \\
\hline Tenure 3 to 5 years & $\begin{array}{c}0.027 \\
(0.003)\end{array}$ & $\begin{array}{c}0.026 \\
(0.004)\end{array}$ & - & - \\
\hline Tenure 5 to 10 years & $\begin{array}{c}0.061 \\
(0.004)\end{array}$ & $\begin{array}{c}0.061 \\
(0.004)\end{array}$ & $\begin{array}{c}0.039 \\
(0.004)\end{array}$ & $\begin{array}{c}0.045 \\
(0.004)\end{array}$ \\
\hline Tenure 10 to 15 years & $\begin{array}{c}0.084 \\
(0.005)\end{array}$ & $\begin{array}{c}0.084 \\
(0.005)\end{array}$ & $\begin{array}{c}0.062 \\
(0.005)\end{array}$ & $\begin{array}{c}0.069 \\
(0.004)\end{array}$ \\
\hline Tenure 15 to 25 years & $\begin{array}{c}0.085 \\
(0.006)\end{array}$ & $\begin{array}{c}0.086 \\
(0.006)\end{array}$ & $\begin{array}{c}0.072 \\
(0.006)\end{array}$ & $\begin{array}{c}0.073 \\
(0.006)\end{array}$ \\
\hline Tenure 25 years or above & $\begin{array}{l}0.120 \\
(0.010)\end{array}$ & $\begin{array}{c}0.121 \\
(0.009)\end{array}$ & $\begin{array}{c}0.097 \\
(0.010)\end{array}$ & $\begin{array}{c}0.105 \\
(0.009)\end{array}$ \\
\hline Unskilled & - & - & - & - \\
\hline Skilled worker & $\begin{array}{c}0.045 \\
(0.010)\end{array}$ & $\begin{array}{c}0.044 \\
(0.010)\end{array}$ & $\begin{array}{c}0.034 \\
(0.011)\end{array}$ & $\begin{array}{c}0.043 \\
(0.010)\end{array}$ \\
\hline $\begin{array}{l}\text { Short theoretical } \\
\text { education }\end{array}$ & $\begin{array}{c}0.060 \\
(0.010)\end{array}$ & $\begin{array}{c}0.062 \\
(0.010)\end{array}$ & $\begin{array}{c}0.046 \\
(0.011)\end{array}$ & $\begin{array}{c}0.058 \\
(0.010)\end{array}$ \\
\hline Bachelor degree & $\begin{array}{c}0.074 \\
(0.010)\end{array}$ & $\begin{array}{c}0.075 \\
(0.010)\end{array}$ & $\begin{array}{c}0.066 \\
(0.012)\end{array}$ & $\begin{array}{c}0.073 \\
(0.011)\end{array}$ \\
\hline Masters or PhD degree & $\begin{array}{c}0.107 \\
(0.011)\end{array}$ & $\begin{array}{c}0.103 \\
(0.011)\end{array}$ & $\begin{array}{c}0.102 \\
(0.013)\end{array}$ & $\begin{array}{c}0.101 \\
(0.012)\end{array}$ \\
\hline Non-management & - & - & - & - \\
\hline Managers & $\begin{array}{c}0.006 \\
(0.007)\end{array}$ & $\begin{array}{c}0.012 \\
(0.007)\end{array}$ & $\begin{array}{c}0.014 \\
(0.008)\end{array}$ & $\begin{array}{c}0.015 \\
(0.008)\end{array}$ \\
\hline Vice presidents & $\begin{array}{c}0.285 \\
(0.015)\end{array}$ & $\begin{array}{l}0.299 \\
(0.015\end{array}$ & $\begin{array}{c}0.309 \\
(0.015)\end{array}$ & $\begin{array}{c}0.307 \\
(0.015)\end{array}$ \\
\hline Demographic variables & YES & YES & YES & YES \\
\hline Job category & YES & YES & YES & YES \\
\hline Time dummies & YES & YES & YES & YES \\
\hline R-squared & 0.865 & 0.878 & 0.890 & 0.885 \\
\hline \# observations & 145,717 & 104,413 & 31,971 & 66,180 \\
\hline
\end{tabular}

Table 6: Mincer wage equations

Second, symmetric learning, first investigated by Farber and Gibbons [1996], offers an alternative explanation. Under symmetric learning, outside firms can be expected to condition offers on the very same signals as the currently employing firm. In the context of the theoretical model, and given the empirical evidence provided in Table 6, the relevant quality signals are education, bonus payments, survival in the firm, and promotions. As potential outside employers observe these signals, the employee's alternative option $(\bar{U})$ becomes a function of the employee's perceived type. Raising $\bar{U}$, could, in principle, raise the fixed wage in order to secure that the 
participation constraint continues to be satisfied.

The third explanation is based on asymmetric learning, with probabilistic outside offers. If outside firms cannot observe bonus payments within the firm, the firm still might want to increase the fixed wage for those employees who are more likely to be of high ability. Let us suppose, for instance, that outside firms are uncertain, with respect to the worker's quality, and give imprecise, probabilistic offers. Thus, sometimes, good employees leave the firm for alternative jobs. Yet, if the firm learns about the type of the worker, it might increase the wages of those employees who are likely to be of high ability. The reason to do this is that the firm can reduce the probability of high-quality employees leaving the firm. Thus, probabilistic outside offers can also lead to wage increases in perceived type, as predicted above. The advantage of the probabilistic outside-offer explanation is that it does not necessarily require that the current firm and outside firms have the same information about employees. ${ }^{31}$

In sum, a variety of explanations are available to answer how signals create fixed-wage dynamics. These theories imply that our job-assignment model can be extended to capture wage dynamics. Yet, to step further, more research is needed on firm-level data in order to evaluate the relative merits of the above theories. At this stage, we can only say that wage dynamics can be made consistent with the model.

\section{Conclusion}

Firms are known to offer highly complex incentive contracts to their employees. Such contracts most often contain fixed wages, bonus payments, promotions, and layoffs. In this paper, we aim at understanding why firms prefer such an incentive mix. In order to do so, a theoretical model is built, and subsequently it is tested on personnel data. The key result is that firms that are concerned about the quality of the workforce have an interest in using the full incentive mix. In particular, these firms use firing, because it contributes to selection, besides its incentive role.

This finding is important for two reasons. First, it shows that regulating firing has profound implications for firm profitability. The reason is that quality-concerned firms might want to fire badly performing employees, even when the level of employment is constant, to improve the average quality of their workforce. Thus, labor-market regulations limiting firing might well put these quality concerned firms at a comparative disadvantage when competing on the international market.

Second, this paper refocuses attention on firing in personnel economics by illustrating that firing has profound and unexpected consequences. For instance, it is shown theoretically, that positive selection on tenure within a given rank is a possibility. This finding, which is supported by the data, challenges previous research in the area.

In addition, this paper shows that a hierarchy of incentives prevails. In particular, firms with homogeneous employees, or without quality concern, would like to introduce incentives in the following order: promotions, bonuses, and, finally, fixed wages. Promotions are preferred over bonuses, because they use free, residual incentives, such as managerial rent. This rent can be exploited through promotions to elicit effort from the lower ranks. Fixed-wages, absent firing, do

\footnotetext{
${ }^{31}$ Asymmetric information could, in principle, lead to strategic rewards; that is, the current employer may give bonuses and promote strategically. The reason is that bonuses and promotions are signals to the market about the employee's quality. Waldman [1985] argues that these concerns may lead to inefficiencies.
} 
not provide incentives, yet they might be necessary to secure employee participation, if bonuses and promotions prove to be insufficient. In contrast, when firms are concerned about the quality and allocation of the workforce as is the case in the job-assignment model the hierarchy of incentives is modified. The reason is that firing together with promotions contribute to sorting and selection of the employees hence firing becomes essential for profit maximization. Consequently, bonuses will only be used to provide additional incentives besides the ones given by promotion and firing.

This paper also uses the optimal contract to derive predictions about the employee's career dynamics within the firm. These predictions describe the probability of receiving bonus payments, promotion, and layoff for the individual employee. In the empirical analysis, they are found to be consistent with the empirical evidence. The success in testing a broad set of predictions, besides the single prediction of the incentive mix allow us to state that the paper accommodates the Gibbons and Waldman critique.

In conclusion, this paper casts a fresh new light on employee incentives by investigating them in a joint empirical-theoretical framework. The results advance our understanding of the incentive role of firing in firms and its consequences for employee selection. Equally important, the paper paves the way for future research. In particular, including other building blocks besides job-assignment, it contributes to an improved understanding of observed firm behavior. 


\section{Appendix}

\subsection{Proofs}

Proof of Lemma (1). Notice that with binding constraints the profit is a function of the firing probability:

$$
\begin{aligned}
& (\theta+\delta) C+F-\overbrace{e+(\theta+\delta)\left[b+\frac{1}{H(\theta+\delta)} U_{P}\right]-(1-\theta-\delta) \pi_{F} U_{F}-\bar{U}}^{w} \\
& -(\theta+\delta) b-\left[(1-\theta-\delta) \pi_{F}+\frac{1}{H}\right] K
\end{aligned}
$$

and that the bonus $(b)$ is canceling out of the equation. Then the first-order condition, in terms of the firing parameter, can be written as:

$$
-(1-\theta-\delta)\left(U_{F}+K\right)<0
$$

Thus, firing is minimized in equilibrium.

Proof of Lemma (2). Consider second period employee quality $\left(\mu_{F}\right)$ first. Notice, that determining the volume of good quality employees determines employee quality as the firm employs a unit volume of employees. Thus, the equilibrium proportion can be determined as the sum of good employees newly hired into non-management and the number of good employees surviving to the second period.

$$
\begin{aligned}
\mu_{F}= & \underbrace{\mu \overbrace{\left[\left(1-\theta_{B}-\mu\left(\theta_{G}-\theta_{B}\right)-\delta\right) \pi_{F}+\left(\theta_{B}+\mu\left(\theta_{G}-\theta_{B}\right)+\delta\right)\right]}^{\# \text { of newly hired }}}_{\# \text { of goods newly hired }} \\
& +\underbrace{\mu-\left(1-\theta_{G}-\delta\right) \mu \pi_{F}-\left(\theta_{G}+\delta\right) \mu \pi_{P}}_{\text {\# of goods surviving }}
\end{aligned}
$$

Straightforward simplification yields the result in (4).

Managers are promoted either internally or externally. The quality of managers can be determined along a similar logic used above to determine employee quality. The number of good promoted employees should be divided by the number of managers $(1 / H)$. The number of internally promoted managers is given by:

$$
\pi_{P} \mu\left(\theta_{G}+\delta\right)
$$

Next, note that externally hire managers have an average quality $\mu$. The volume of external hiring is given

$$
\left(\frac{1}{H}-\pi_{P}\left(\mu \theta_{G}+(1-\mu) \theta_{B}+\delta\right)\right)
$$

Thus, the volume of externally promoted good quality managers is:

$$
\mu\left(\frac{1}{H}-\pi_{P}\left(\mu \theta_{G}+(1-\mu) \theta_{B}+\delta\right)\right)
$$

Combining the terms yields the solution. 
Finally, to see that $\mu_{F}$ is increasing in the firing rate, differentiate (4) with respect to $\pi_{F}$.

Proof of Lemma (3). The proof of the lemma follows from the discussion preceding it. It is straightforward to show parameter values where the incentive mix arises and is left to the reader.

Proof of Lemma (4). To see that selection on rank is positive, notice first that in equilibrium, the promotion constraint is binding, then:

$$
\mu_{M}=\frac{\mu\left(\theta_{G}+\delta\right)}{\theta_{B}+\mu\left(\theta_{G}-\theta_{B}\right)+\delta} \geq \mu+\mu(1-\mu)\left(\theta_{G}-\theta_{B}\right)\left(\pi_{F}-\pi_{P}\right)=\mu_{F}
$$

which expression can be simplified to

$$
1 \geq\left(\pi_{F}-\pi_{P}\right)\left(\theta_{B}+\mu\left(\theta_{G}-\theta_{B}\right)+\delta\right)
$$

where both terms on the right hand side are smaller than unity.

To see the statement on the selection on tenure, focus on the employees staying in employee rank, after the first period. The number of surviving employees is given by:

$$
1-\left(\theta_{B}+\mu\left(\theta_{G}-\theta_{B}\right)+\delta\right) \pi_{P}-\left(1-\theta_{B}-\mu\left(\theta_{G}-\theta_{B}\right)-\delta\right) \pi_{F}
$$

The number of surviving good ability employees is given by:

$$
\mu\left[1-\left(\theta_{G}+\delta\right) \pi_{P}-\left(1-\theta_{G}-\delta\right) \pi_{F}\right]
$$

Thus, the quality composition of tenured employees can be written as:

$$
\mu_{T}=\mu \frac{1-\left(\theta_{G}+\delta\right) \pi_{P}-\left(1-\theta_{G}-\delta\right) \pi_{F}}{1-\left(\theta_{B}+\mu\left(\theta_{G}-\theta_{B}\right)+\delta\right) \pi_{P}-\left(1-\theta_{B}-\mu\left(\theta_{G}-\theta_{B}\right)-\delta\right) \pi_{F}}
$$

and it can be rewritten as

$$
\mu_{T}=\mu \underbrace{\frac{\overbrace{1-\left(\theta_{G}+\delta\right) \pi_{P}-\left(1-\theta_{G}-\delta\right) \pi_{F}}^{A}}{\underbrace{1-(1-\mu)\left(\theta_{G}-\theta_{B}\right)\left(\pi_{P}-\pi_{F}\right)}_{1-\left(\theta_{G}+\delta\right) \pi_{P}-\left(1-\theta_{G}-\delta\right) \pi_{F}}}}_{A}
$$

which is trivially higher than $\mu$, if and only if $\pi_{F}>\pi_{P}$.

\subsection{Managerial rent}

The model assumes that managerial rent exists, yet it only handles it in a closed form. Here we provide some reasons for this closed-form representation. There are two major explanations, and both of them build on the same observation, namely that managers affect the work of many subordinates.

The first approach justifies rents by incentives. Calvo and Wellisz (1979) argue that rent is an increasing function of hierarchical rank. Their model is based on costly supervision, where shirking employees are punished by firing. This punishment, however, is only effective as long as there are rents with respect to the job. As managers affect the work of many subordinates, they are given more rents to ensure no shirking. Thus, the firm might be tempted to offer higher compensation for managers, even if the nature of the work is not different, and all the workers 
and managers are identical. In sum, a wage (and rent) ladder might prevail, even absent quality differences.

The second rationale, suggested here, stems from the firm's desire to curb managerial turnover (more than the turnover of the non-management level). The intuition is simple, and again it rests on the observation that managers affect the output of many other employees. If a nonmanagement employee leaves, it disrupts his own output. If a manager leaves, the leave disrupts the output of the manager and all his subordinates. Consequently, the firm would like to give stronger incentives to stay for managers than for workers. If outside offers are probabilistic, rents can be used to induce loyalty. Thus, in this setting, the manager's compensation will include rents (and higher ones than that of the employees).

Finally, managerial rent has empirical support. It is generally understood that employees prefer to be promoted with the ongoing conditions. Thus, managerial work is more desirable, supporting the first incentive explanation. Also, voluntary managerial turnover is lower than voluntary employee turnover, which lends support to the second explanation. In our data set, for instance, lower-level managers and vice-presidents have a 9.80-percent and a 15.35-percent lower turnover, respectively, than do employees.

In conclusion, then, we are comfortable with the closed-form modeling of managerial rents. The available empirical and theoretical evidence seems to support its existence.

\subsection{Action-set conditioning}

Conditioning the action set on output, as it was proposed in the model, is without the loss of generality.

In the basic model, the assumed action setup is general. The fact that the action set was constrained on output realizations does not change the equilibrium. It is straightforward to check that the firm would promote only high-performance employees, and only fire low-performance ones. Similarly, the firm would not pay bonuses to low-performers, even if the action set would allow for that.

Under employee heterogeneity, the firm still prefers to promote well-performing employees, and to lay off individuals with low performance. The reason is twofold. First, promoting wellperforming employees and laying off badly performing ones is useful for incentive purposes. Second, selection considerations also strengthen the promotion and layoff policy. As managerial output is relatively more important than non-managerial output, better-quality employees are more desirable for promotion. Thus, the firm prefers to promote high-performance individuals, as they are more likely to have high ability. Similarly, conditioning layoffs on low performance makes sure that the fired individual is relatively more likely to be of low ability. This improves the overall quality of the workforce, and hence has a positive impact on productivity. Again, it

is straightforward to see that bonuses are only paid to well-performing agents, just like in the homogeneous case. 


\subsection{Additional regressions}

\begin{tabular}{|c|c|c|}
\hline & Layoff & Promotion \\
\hline Constant & $\begin{array}{l}-10.912 \\
(1.023)\end{array}$ & $\begin{array}{l}-8.603 \\
(1.117)\end{array}$ \\
\hline $\begin{array}{l}\text { Bonus payment received } \\
\text { during the preceding year }\end{array}$ & $\begin{array}{l}-2.222 \\
(0.268)\end{array}$ & $\begin{array}{c}0.768 \\
(0.249)\end{array}$ \\
\hline Tenure less than 2 years & - & - \\
\hline Tenure 2 to 5 years & $\begin{array}{c}1.211 \\
(0.736)\end{array}$ & $\begin{array}{c}0.155 \\
(0.388)\end{array}$ \\
\hline Tenure 6 to 10 years & $\begin{array}{c}1.456 \\
(0.736)\end{array}$ & $\begin{array}{c}0.038 \\
(0.412)\end{array}$ \\
\hline Tenure above 10 years & $\begin{array}{c}1.651 \\
(0.734)\end{array}$ & $\begin{array}{l}-0.170 \\
(0.432)\end{array}$ \\
\hline Unskilled & - & - \\
\hline Skilled worker & $\begin{array}{l}-1.314 \\
(0.504)\end{array}$ & $\begin{array}{c}-0.925 \\
(1.225)\end{array}$ \\
\hline Short theoretical education & $\begin{array}{l}-0.589 \\
(0.403)\end{array}$ & $(-)$ \\
\hline Bachelor degree & $\begin{array}{c}0.798 \\
(0.391)\end{array}$ & $\begin{array}{c}1.088 \\
(1.032)\end{array}$ \\
\hline Masters or PhD degree & $\begin{array}{c}0.343 \\
(0.402)\end{array}$ & $\begin{array}{c}1.959 \\
(1.009)\end{array}$ \\
\hline Demographic variables & YES & YES \\
\hline Time dummies & YES & YES \\
\hline $\begin{array}{l}\text { Log likelihood } \\
\text { \# observations }\end{array}$ & & \\
\hline
\end{tabular}

Table 7: Multinomial logit

\begin{tabular}{|c|c|c|c|c|c|}
\hline & \multicolumn{3}{|c|}{ "Logit model } & \multicolumn{2}{|c|}{ Fixed-effects model } \\
\hline & $\begin{array}{c}\text { No restrictions } \\
\text { on tenure }\end{array}$ & $\begin{array}{c}\text { Conditional on } \\
\text { tenure }>1\end{array}$ & $\begin{array}{c}\text { Conditional on } \\
\text { tenure }>2\end{array}$ & $\begin{array}{c}\text { Conditional on } \\
\text { tenure }>1\end{array}$ & $\begin{array}{c}\text { Conditional on } \\
\text { tenure }>2\end{array}$ \\
\hline Constant & $\begin{array}{l}-4.304 \\
(0.580)\end{array}$ & $\begin{array}{l}-4.131 \\
(0.636)\end{array}$ & $\begin{array}{l}-4.459 \\
(0.698)\end{array}$ & - & - \\
\hline Tenure & $\begin{array}{c}0.022 \\
(0.004)\end{array}$ & $\begin{array}{c}0.015 \\
(0.005)\end{array}$ & $\begin{array}{c}0.014 \\
(0.005)\end{array}$ & $\begin{array}{c}0.061 \\
(0.117)\end{array}$ & $\begin{array}{c}0.135 \\
(0.172)\end{array}$ \\
\hline Non-management & - & - & - & - & - \\
\hline Managers & $\begin{array}{c}0.722 \\
(0.184)\end{array}$ & $\begin{array}{c}0.726 \\
(0.192)\end{array}$ & $\begin{array}{c}0.762 \\
(0.197)\end{array}$ & $\begin{array}{c}0.704 \\
(0.483)\end{array}$ & $\begin{array}{c}0.780 \\
(0.541)\end{array}$ \\
\hline Vice presidents & $\begin{array}{c}1.665 \\
(0.382)\end{array}$ & $\begin{array}{c}1.662 \\
(0.384)\end{array}$ & $\begin{array}{c}1.622 \\
(0.385)\end{array}$ & $\begin{array}{c}0.735 \\
(1.117)\end{array}$ & $\begin{array}{c}0.764 \\
(1.114)\end{array}$ \\
\hline Unskilled & - & - & - & & \\
\hline Skilled worker & $\begin{array}{c}0.389 \\
(0.160)\end{array}$ & $\begin{array}{c}0.357 \\
(0.165)\end{array}$ & $\begin{array}{c}0.373 \\
(0.170)\end{array}$ & & \\
\hline $\begin{array}{l}\text { Short theoretical } \\
\text { education }\end{array}$ & $\begin{array}{c}0.450 \\
(0.159)\end{array}$ & $\begin{array}{c}0.398 \\
(0.163)\end{array}$ & $\begin{array}{c}0.432 \\
(0.168)\end{array}$ & & \\
\hline Bachelor degree & $\begin{array}{c}0.408 \\
(0.165)\end{array}$ & $\begin{array}{c}0.378 \\
(0.171)\end{array}$ & $\begin{array}{c}0.414 \\
(0.177)\end{array}$ & & \\
\hline $\begin{array}{l}\text { Masters or } \mathrm{PhD} \\
\text { degree }\end{array}$ & $\begin{array}{c}0.633 \\
(0.187)\end{array}$ & $\begin{array}{c}0.604 \\
(0.198)\end{array}$ & $\begin{array}{c}0.693 \\
(0.207)\end{array}$ & & \\
\hline $\begin{array}{l}\text { Demographic } \\
\text { variables }\end{array}$ & YES & YES & YES & YES & YES \\
\hline Job category & YES & YES & YES & YES & YES \\
\hline Time dummies & YES & YES & YES & YES & YES \\
\hline Log likelihood & $-5,964$ & $-5,230$ & $-4,763$ & $-1,741$ & $-1,561$ \\
\hline \# observations & 10,801 & 9,674 & 8,872 & 5,740 & 5,167 \\
\hline
\end{tabular}

Table 8: Bonus regression 


\section{References}

[1] Baker, G. P., M. Gibbs and B. Holmström (1994a) "Subjective performance measures in optimal incentive contracts" the Quarterly Journal of Economics, 109, pp. 881-919.

[2] Baker, G. P., M. Gibbs and B. Holmström (1994b) "The wage policy of the firm" the Quarterly Journal of Economics, 109, pp. 921-55.

[3] Becker, G. S. (1964) Human Capital, 1st ed., New York: the National Bureau of Economic Research.

[4] Calvo, G. A., and S. Wellisz (1979) "Hierarchy, ability and income distribution" the Journal of Political Economy, vol. 87, no 5, pp. 991-1010.

[5] Doeringer, P., and M. Piore (1971) "Internal Labor Markets and Manpower Analysis" Lecington, MA: D. C. Heath and Company.

[6] Farber, H. S., and R. S. Gibbons (1996) "Learning and wage dynamics" the Quarterly Journal of Economics, 111, pp. 1007-47.

[7] Gibbons, R. S., and M. Waldman (1999a) "A theory of wage and promotion dynamics inside firms" the Quarterly Journal of Economics, November 1999.

[8] Gibbons, R. S., and M. Waldman (1999b) "Careers in organizations: theory and evidence" in Ashenfelter, Orley and Card, David, 1999, Handbook of Labor Economics, 3B, Ch. 35, Elsevier.

[9] Gibbons, R. S., and M. Waldman (2003) "Enriching a theory of wage and promotion dynamics inside firms"

[10] Gibbs, M. 1995, "Incentive compensation in a corporate hierarchy," the Journal of Accounting and Economics, 19, pp. 247-277.

[11] Guasch, J. L., and A. Weiss (1980) "Wages as a sorting mechanism in competitive markets with asymmetric information: a theory of testing" the Review of Economic Studies, vol. 47, no. 4, pp. 653-64.

[12] Holmström, B. (1979) "Moral hazard and observability" Bell Journal of Economics, 9, pp. 74-91.

[13] Holmström, B. (1982) "Moral hazard in teams" Bell Journal of Economics, 13, pp. 324-40.

[14] Lazear, E. P. (1989) "Pay equality and industrial politics" Journal of Political Economy, 97, pp. 561-80.

[15] Lazear, E. P. (1992) "The job as a concept" in W. Bruns, ed., "Performance measurement, evaluations, and incentives" (Harvard University Press, Boston, MA), pp. 183-215.

[16] Lazear, E. P. (2000) "Performance Pay and Productivity" the American Economic Review 90, pp. 1346-61. 
[17] Lazear, E. P., and S. Rosen (1981)

"Rank-order tournaments as optimum labour contracts" Journal of Political Economy, 89, pp. 841-64.

[18] MacLeod, W. B., and J. M. Malcolmson (1998) "Motivation and markets" the American Economic Review, 88 (3), pp. 388-411.

[19] MacLeod, W. B., and D. Parent (1999) "Job Characteristics and the Form of Compensation" Research in Labor Economics, 18: 177-242.

[20] Medoff, J., and K. Abraham (1980) "Experience, performance, and earnings" Quarterly Journal of Economics, 95, pp. 703-36.

[21] Medoff, J., and K. Abraham (1981) "Are those paid more really more productive?" Journal of Human Resources, 16, pp. 186-216.

[22] Mirrlees, J. (1974) "Notes on welfare economics, information, and uncertainty" in Essays on economic behavior under uncertainty, M. Balch, D. McFadden and S. Wu, eds., North Holland, Amsterdam, pp. 243-58.

[23] Mirrlees, J. (1976) "The optimal structure of incentives and authority within an organization" Bell Journal of Economics, 7, pp. 105-31.

[24] Shapiro, C., and J. E. Stiglitz (1984) "Equilibrium unemployment as a worker discipline device" American Economic Review, vol. 74, pp. 433-44.

[25] Waldman, M. (1984) "Job Assignments, Signalling, and Efficiency" Rand Journal of Economics, vol. XV, pp. 255-67. 